\title{
STABILITY ESTIMATION METHOD FOR ARMOR UNITS FOR BREAKWATERS WITH PARAPETS AGAINST TSUNAMI OVERFLOW
}

\author{
Jun Mitsui $^{1}$, Shin-ichi Kubota ${ }^{1}$ and Akira Matsumoto ${ }^{1}$
}

\begin{abstract}
This paper presents a stability estimation method for armor units to cover a rubble mound on the rear side of a caisson breakwater against tsunami overflow while taking into account the influence of the shape of the superstructures of the caisson. In this method, the required mass of the armor units is obtained from the impinging velocity onto the rear side mound. This is calculated by using the overflow depth. Accordingly, the influence of the shape of the superstructure is taken into account directly. This method also takes the influence of the slope angle into account properly by using the formula by Isbash. In addition, the influence of the impingement position of the overflow nappe and the influence of the thickness of the water jet are considered. The validity of this method is confirmed by comparing with the results of hydraulic model experiments conducted in a wide range of conditions.
\end{abstract}

Keywords: tsunami; overflow; caisson breakwater; parapet; armor units; stability

\section{INTRODUCTION}

The huge tsunami generated by the 2011 off the Pacific coast of Tohoku Earthquake brought severe damage to caisson breakwaters in Japan. One of the failure mechanisms of breakwaters was scouring of the rear side rubble mound and subsoil behind the caisson due to overflow. As a countermeasure against a large tsunami in the future, resilient breakwaters against such a tsunami are requested. One possible method is the placement of a widened protection mound using additional rubble stones behind the caisson to increase the resistance against sliding. Installing armor units on the rubble mounds on the rear side would also be required to prevent scouring of the rubble mound. In addition, installing a parapet on the caisson would be also effective because the parapet would redirect the overtopped water flow in the horizontal direction (Satoh et al. 2012, Higashiyama et al. 2013).

In design work, it is required to determine the mass of the armor units which is needed to ensure stability against tsunami overflow. The Isbash formula (Coastal Engineering Research Center [CERC] 1977) which determines the required mass of armor units based on the flow velocity has so far been applied. This formula is expressed as follows:

$$
M=\frac{\pi \rho_{r} U^{6}}{48 g^{3} y^{6}\left(S_{r}-1\right)^{3}(\cos \theta-\sin \theta)^{3}}
$$

where, $M$ is the required mass of the armor units, $\rho_{r}$ is the density of the armor units, $U$ is the flow velocity near the armor units, $g$ is the gravitational acceleration, $y$ is the Isbash number representing the stability of the armor units, $S_{r}$ is the specific gravity of the armor unit with respect to water, and $\theta$ is the angle of slope. For example, Arikawa et al. (2014) conducted physical experiments on armor stability and investigated the applicability of the formula against tsunami overflow. However, it would take a lot of labor and time to use such a design method based on the flow velocity because it is necessary to conduct numerical computation to obtain the flow velocity near the armor units. In addition, there is a practical problem that the required mass is too sensitive to variations in the estimated flow velocity because the required mass is proportional to the sixth power of the flow velocity according to this formula.

On the other hand, the authors have proposed a simple stability estimation method based on the overflow depth (Mitsui et al. 2014). In this method, the overflow depth of tsunami is used to represent the external force acting on the armor units. This enables the estimation of the required mass of the armor units to be done more robustly and easily. However, the applicable range of this method is limited to the rectangular caisson.

In this new study, we propose a new stability estimation method applicable to the caisson with various sizes of parapet. This method can directly capture the influence of the parapet on the armor stability, while retaining advantages such as the simplicity and robustness of our previous method based on the overflow depth. First, we will describe hydraulic model experiments on the stability of armor units against tsunami overflow using a rectangular caisson and a caisson with parapet. Next, the basic concept of the newly developed stability estimation method and specific procedure will be described. Finally, the validity of the method will be described by comparison with experimental results.

\footnotetext{
${ }^{1}$ Technical Research Institute, Fudo Tetra Corporation, 2-7, Higashi-nakanuki, Tsuchiura, Ibaraki, 300-0006, Japan, jun.mitsui@fudotetra.co.jp
} 


\section{HYDRAULIC MODEL EXPERIMENTS}

\section{Method}

A series of experiments was conducted in a $50 \mathrm{~m}$ long, $1.0 \mathrm{~m}$ wide and $1.5 \mathrm{~m}$ deep wave flume at the Technical Research Institute of Fudo Tetra Corporation. The test setup is shown in Fig. 1. A horizontal mortar seabed was partitioned into two sections along the length, and a breakwater model was installed in one $50 \mathrm{~cm}$ wide waterway. A steady overflow was generated by using a pump. The height of the sea-side water level could be changed by varying the height of the overflow weir installed on the sea-side of the breakwater model.

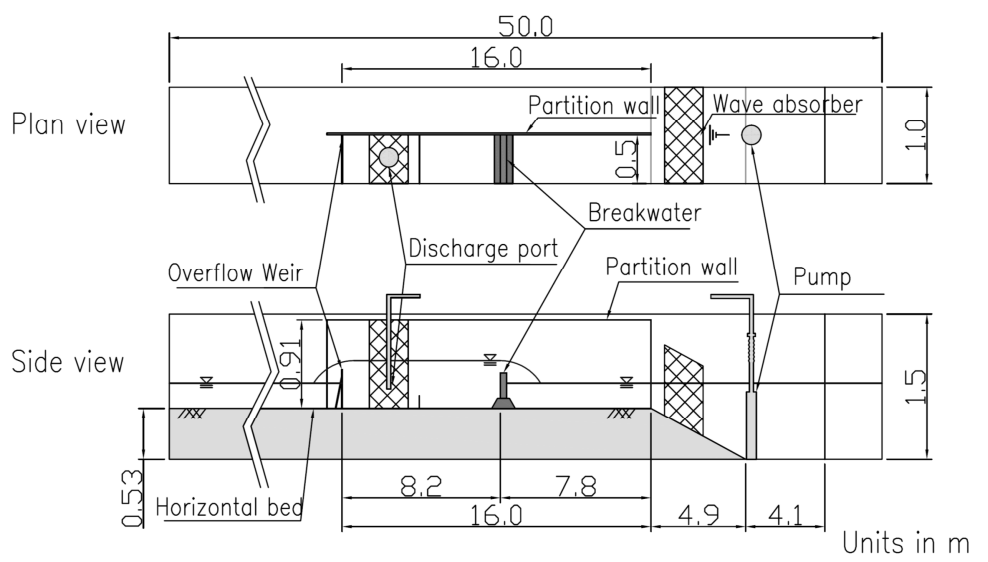

Figure 1. Test setup in the flume.

A schematic layout of the breakwater model is shown in Fig. 2. The model scale was 1/50. Two types of breakwaters for relatively deep water conditions (Breakwater-A) and shallow water conditions (Breakwater-B) were used. Experiments were carried out by changing the presence or absence of parapet, the presence or absence of a widened protection mound, harbor-side water level, and the shape and mass of the armor units. Two kinds of flat-type armor blocks and two kinds of wave-dissipating concrete blocks were used (see Fig. 3). The X-block is a flat-type armor block widely used in Japan for covering the rubble mounds of breakwaters (e.g. Matsuda et al. 2000). Permex is a recently developed armor block from refining the X-block. The large holes in the Permex have been found to contribute to high stability against wave action due to the reduction of the uplift force (Hamaguchi et al. 2007). The Tetraneo is also a recently developed wave-dissipating block based on the Tetrapod. The large projection on the tip of the legs of the Tetraneo realizes a high interlocking effect resulting in high hydraulic stability (Matsumoto et al. 2016). Flat-type armor blocks (Permex and X-block) were placed in one layer and wave-dissipating concrete blocks (Tetraneo and Tetrapod) were placed in two layers. The height of parapet was $4 \mathrm{~cm}$, but in some cases a parapet with a height of $8 \mathrm{~cm}$ was used. The caisson model was fixed with a weight so that it would not be moved by tsunami action since this study was focused on the stability of armor units. Experimental conditions are summarized in Table 1.

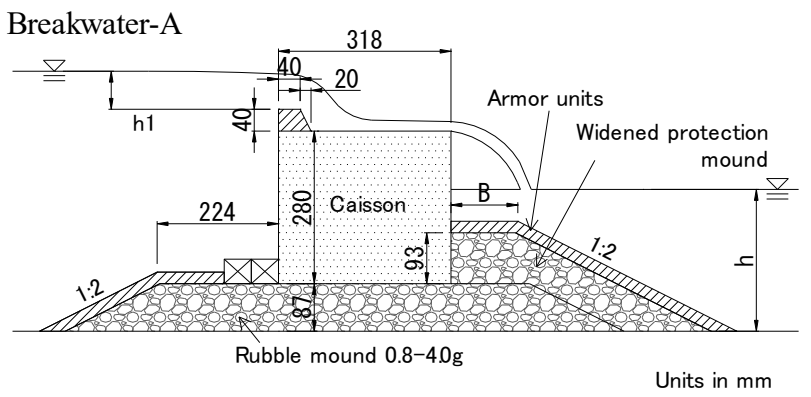

Breakwater-B

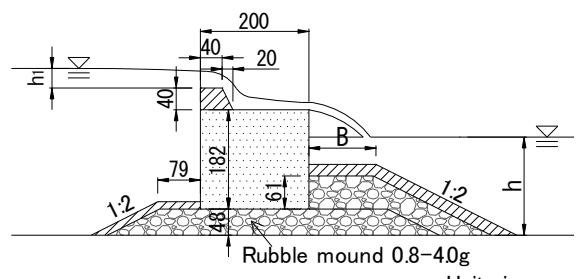

Figure 2. Cross sections of the tested breakwaters. 

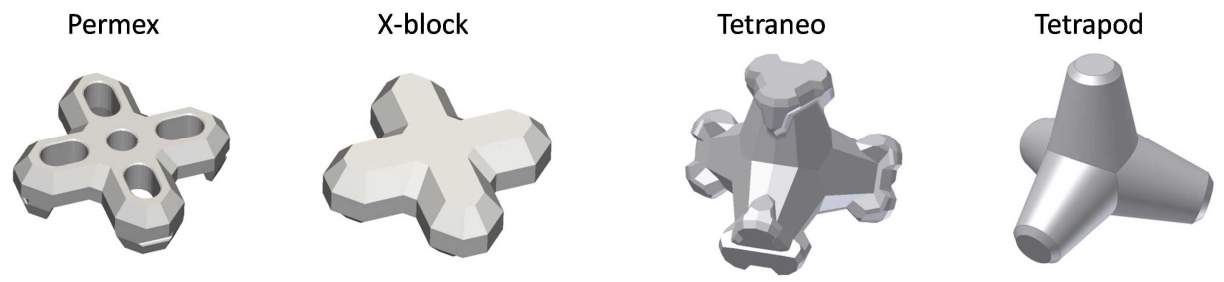

Figure 3. Armor units used in the experiments.

\begin{tabular}{|c|c|c|c|c|c|c|c|}
\hline $\begin{array}{l}\text { Armor } \\
\text { units }\end{array}$ & $\begin{array}{l}\text { Break- } \\
\text { water }\end{array}$ & $\begin{array}{c}\text { Super- } \\
\text { structure }\end{array}$ & $\begin{array}{l}\text { Widened } \\
\text { protection }\end{array}$ & $h(\mathrm{~cm})$ & $M(g)$ & $B(\mathrm{~cm})$ & $\begin{array}{l}\text { Number } \\
\text { of cases }\end{array}$ \\
\hline \multirow{8}{*}{ Permex } & \multirow{6}{*}{ A } & \multirow{2}{*}{ Rectangular } & O & 26,30 & 16,65 & $11.7-36.3$ & 8 \\
\hline & & & - & 26,30 & 16,65 & $12.9-53.2$ & 12 \\
\hline & & \multirow{2}{*}{ Parapet } & 0 & 26,30 & 16,65 & $11.7-36.3$ & 10 \\
\hline & & & - & 26,30 & 65 & $17.4-53.2$ & 6 \\
\hline & & \multirow{2}{*}{$\begin{array}{c}\text { Parapet } \\
\text { (large) }\end{array}$} & 0 & 26 & 65 & $12.4-36.3$ & 3 \\
\hline & & & - & 26 & 65 & $17.4-53.2$ & 2 \\
\hline & \multirow{2}{*}{ B } & Rectangular & 0 & 18,20 & 16,65 & $7.9-24.3$ & 6 \\
\hline & & Parapet & $\bigcirc$ & 18,20 & 16,65 & $7.9-24.3$ & 6 \\
\hline \multirow{7}{*}{ X-block } & \multirow{5}{*}{ A } & \multirow{2}{*}{ Rectangular } & 0 & 26,30 & 16,66 & $6.8-21.1$ & 7 \\
\hline & & & - & 26,30 & 16,66 & $11.8-46.9$ & 9 \\
\hline & & \multirow{2}{*}{ Parapet } & 0 & 26,30 & 66 & $10.7-21.1$ & 6 \\
\hline & & & - & 26,30 & 66 & $15.7-46.9$ & 6 \\
\hline & & $\begin{array}{c}\text { Parapet } \\
\text { (Large) }\end{array}$ & 0 & 26 & 66 & $10.7-31.5$ & 2 \\
\hline & \multirow{2}{*}{ B } & Rectangular & 0 & 18,20 & 16,66 & $6.8-21.1$ & 6 \\
\hline & & Parapet & 0 & 18,20 & 16,66 & $6.8-21.1$ & 6 \\
\hline \multirow{6}{*}{ Tetraneo } & \multirow{4}{*}{ A } & \multirow{2}{*}{ Rectangular } & 0 & 26,30 & 48,241 & $10.5-45.0$ & 9 \\
\hline & & & - & 26,30 & 48,241 & $15.0-45.0$ & 12 \\
\hline & & \multirow{2}{*}{ Parapet } & 0 & 26,30 & 48,241 & $10.5-11.4$ & 4 \\
\hline & & & - & 26,30 & 48,241 & $15.0-45.0$ & 8 \\
\hline & \multirow{2}{*}{ B } & Rectangular & 0 & 18,20 & 16,48 & $4.2-6.2$ & 4 \\
\hline & & Parapet & 0 & 18,20 & 16,48 & $4.2-6.2$ & 4 \\
\hline \multirow{8}{*}{ Tetrapod } & \multirow{4}{*}{ A } & \multirow{2}{*}{ Rectangular } & $\mathrm{O}$ & 26,30 & 59,230 & $6.8-45.0$ & 12 \\
\hline & & & - & 26,30 & 59,230 & $15.0-45.0$ & 12 \\
\hline & & \multirow{2}{*}{ Parapet } & 0 & 26,30 & 59,230 & $6.8-11.6$ & 4 \\
\hline & & & - & 26,30 & 59,230 & $15.0-45.0$ & 8 \\
\hline & \multirow{4}{*}{ B } & \multirow{2}{*}{ Rectangular } & $\bigcirc$ & 18,20 & 15,59 & $4.4-30.0$ & 5 \\
\hline & & & - & 20 & 59 & 30.0 & 1 \\
\hline & & \multirow{2}{*}{ Parapet } & $\bigcirc$ & 18,20 & 15,59 & $4.4-30.0$ & 5 \\
\hline & & & - & 20 & 59 & 30.0 & 1 \\
\hline
\end{tabular}

Note: $h$ represents the harbor-side water depth; $M$ represents the mass of the armor unit; $B$ denotes the crown width of the harbor-side mound.

The time duration of the steady overflow of tsunami was set to $127 \mathrm{~s}(15 \mathrm{~min}$ in the prototype scale). As it took about $60 \mathrm{~s}$ until the water level achieved a steady state from the start of operating the pump, the total operation time of the pump was set to $187 \mathrm{~s}$. The stability limits of the armor units were examined by increasing the overflow depth in increments of $1 \mathrm{~cm}$. The overflow depth was defined as the difference between the sea-side water level (measured at $2 \mathrm{~m}$ on the offshore side from the front of the caisson) and the crest height of the caisson. The harbor-side water level was measured at $2 \mathrm{~m}$ on the onshore side from the rear surface of the caisson. The section was not rebuilt after tsunami attack with each overflow depth. The number of moved armor units was counted as an accumulated number. The damage to armor units was defined using the relative damage $N_{0}$, which is the actual number of displaced units related to the width of one nominal diameter $D_{n}$. The nominal diameter $D_{n}$ is the cube root of the volume of the armor units. In this study, $N_{0}=0.3$ was applied as the criterion of damage. 


\section{Results}

Examples of the experimental results are shown in Fig. 4. The experiments were conducted under the following conditions: breakwater-B, $h=20 \mathrm{~cm}$, Permex $(M=65 \mathrm{~g}), 2$ rows in crown section $(B=$ $12.4 \mathrm{~cm})$. In the case of a rectangular caisson, the armor units were damaged with an overflow depth of $9 \mathrm{~cm}$, while in the case of a caisson with parapet, the damage occurred with an overflow depth of $7 \mathrm{~cm}$. Because the height of the parapet is $4 \mathrm{~cm}$, the height of tsunami at the stability limit was increased by 2 $\mathrm{cm}$ by installing the parapet, but the overflow depth at the stability limit was decreased by $2 \mathrm{~cm}$ due to the installation of the parapet. It can be seen from the pictures of the overflow situation that the water jet impinges onto the water surface at an angle close to horizontal in the case with parapet. In addition, it is supposed that the flow velocity impinging onto the harbor-side water surface is larger than that of the rectangular caisson case since the water above the caisson is accelerated when flowing over the parapet. It is considered necessary to incorporate physical phenomena such as a change in the impinging flow velocity due to the parapet into the stability estimation method to accurately predict the stability.

(a) Rectangular caisson

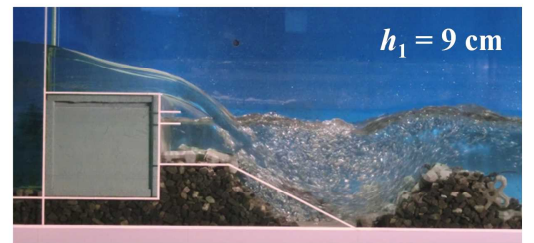

(b) Caisson with parapet

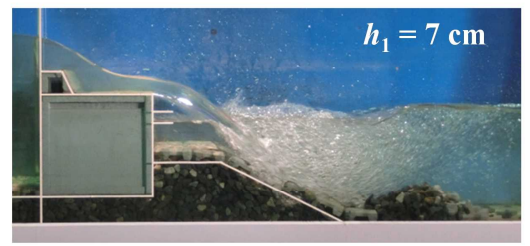

Test conditions: Breakwater-B, $h=20 \mathrm{~cm}$, Permex $(M=65 \mathrm{~g}), 2$ rows in crown section $(B=12.4 \mathrm{~cm})$

Figure 4. Snapshots at the occurrence of damage.

\section{BASIC CONCEPT OF THE STABILITY ESTIMATION METHOD}

The stability estimation method proposed in this study is described below. First, each dimension and hydraulic quantity are represented by the following symbols (see Fig. 5): $B_{c}$ is the caisson width, $H_{p}$ is the parapet height, $B_{p}$ is the parapet width, $d_{1}$ is the harbor-side crown height of the caisson above the harbor-side water level, $d_{2}$ is the submerged depth above the armor units, $B$ is the crown width of the harbor-side mound, $B_{G}$ is the bottom width of the harbor-side mound, $\alpha$ is the slope angle of the mound, $q$ is the overflow discharge per unit width, $h$ is the harbor-side water depth, $h_{1}$ is the overflow depth, $h_{2}$ is the water depth above the caisson at the rear end of the caisson, $u_{2}$ is the flow velocity at the rear end of the caisson, $x_{3}$ is the landing position of the water jet at the harbor-side water surface, $u_{3}$ is the flow velocity at the landing position of the water jet, $b_{0}$ is thickness of the water jet at the harborside water level, $L$ is the impingement position of the water jet on the top of the harbor-side mound, $L_{G}$ is the impingement position of the water jet at the seabed, $U$ is the impinging flow velocity onto the armor units, $b_{1}$ is the thickness of the water jet at the impingement position onto the armor units, $\bar{x}$ is the distance from the landing position of the water jet at the water surface to the impingement position onto the armor units, $x_{p}$ and $z_{p}$ are the coordinates of the impingement position onto the armor units. The coordinate system is defined with a horizontal $x$ axis (landward positive) and a vertical $z$ axis (upward positive). Let $x=0$ at the rear end of the caisson, and $z=0$ at the harbor-side water level. Subscripts $x$ and $z$ mean horizontal and vertical components, respectively. 


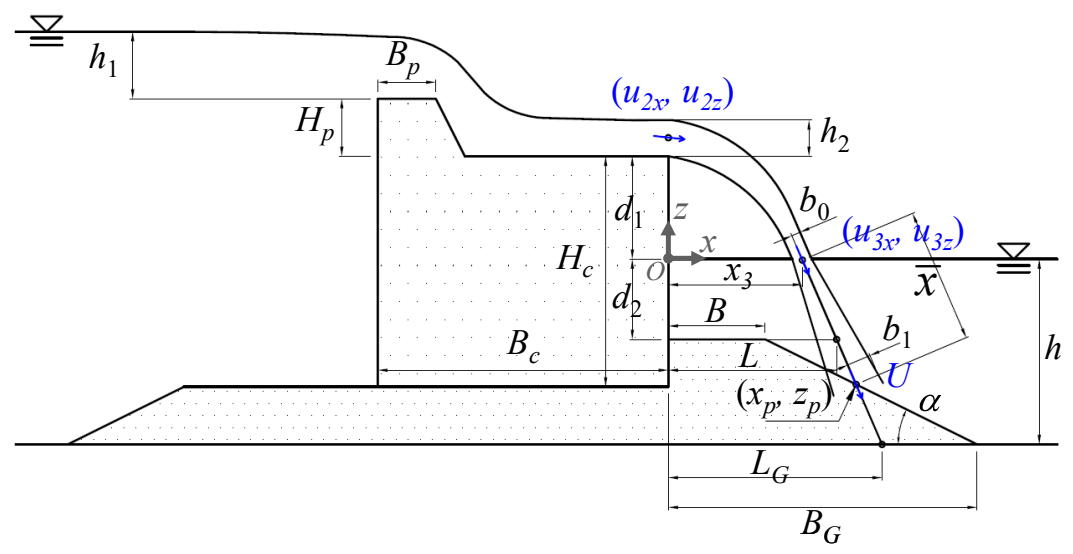

Figure 5. Definition of the symbols for each dimension and hydraulic quantity.

The proposed method can be divided into two successive parts. The former is to calculate the impinging flow velocity onto the mound $U$, and the latter is to calculate the required mass using the flow velocity. The specific method of calculating the impinging flow velocity is described in the next chapter, but it is easily calculated using the overflow depth in sequence through the rear end of the caisson, the landing position of the overflow nappe on the harbor-side water surface, and the impinging position onto the armor units. As mentioned above, there is a problem with the conventional method that the calculated required mass varies largely depending on the measurement position of the flow velocity and the measurement error. However, by using the flow velocity obtained from the overflow depth, it becomes possible to eliminate the variation in the calculated required mass. In addition, a direct grasp of the influence of the superstructure shape on the armor stability is enabled in this new method because the difference in the superstructure shape is reflected on to the impinging flow velocity. For the relationship between the flow velocity and the required mass of the armor units, the formula shown in the original article by Isbash (1932) is applied instead of the formula by CERC (1977).

$$
M=\frac{\pi \rho_{r} U^{6}}{48 g^{3} Y^{6}\left(S_{r}-1\right)^{3} \cos ^{3} \theta}
$$

where, the Isbash number is denoted as $Y$ to distinguish it from the Isbash number $y$ in Eq. 1 from CERC (1977). As can be seen above, Eq. 1 and Eq. 2 have different expressions for the influence of the slope angle. The past study by the authors showed that the formula from CERC (1977) tends to overestimate the influence of the slope angle when applied to concrete blocks because of the presence of interlocking between the blocks (Mitsui et al. 2016). On the other hand, the original formula by Isbash (1932) takes this influence into account more properly. For this reason, we adopted Eq. 2 in the stability estimation method. The angle of slope $\theta$ in the Eq. 2 is selectively used depending on the impingement position of the overtopped water jet as follows:

$$
\theta=\left\{\begin{array}{lll}
0 & : L \leq B & \text { (Jet impinges on crown section) } \\
\alpha & : L>B & \text { (Jet impinges on slope section) }
\end{array}\right.
$$

To incorporate phenomena peculiar to tsunami overflow into the calculation of the required mass, some contrivances are made as described below. The first one is to incorporate the difference in resistance of armor units due to the impingement position of the water jet. In the case of a tsunami overflow, armor stability varies depending on the impingement position since the part where the fluid force acts is limited to only a part of the mound. For example, the armor units at the shoulder of the mound or at the toe of the mound have a relatively low resistance to external forces because the back support is weak in these parts. The influence of the impingement position is taken into account by introducing the reduction coefficient $C_{R}$ of the Isbash number according to the impingement position as follows:

$$
Y=C_{R} Y_{0}
$$




$$
C_{R}=\min \left(C_{R 1}, C_{R 2}\right)
$$

in which, $Y_{0}$ is the Isbash number before considering $C_{R}$, and $C_{R 1}, C_{R 2}$ are the reduction coefficients indicating the influence of the shoulder of the mound and the toe of the mound respectively. These coefficients were set as shown in Eq. 6, Eq.7, and Fig. 6. These coefficients are determined by trial and error so as to be suitable with the experimental results.

$$
\begin{gathered}
C_{R 1}=1-\frac{0.2}{\cosh \left\{0.8\left(\frac{L-B}{D_{n}}+2\right)\right\}} \\
C_{R 2}=1-\frac{0.3}{\cosh \left\{0.8 \frac{L_{G}-B_{G}}{D_{n}}\right\}}
\end{gathered}
$$
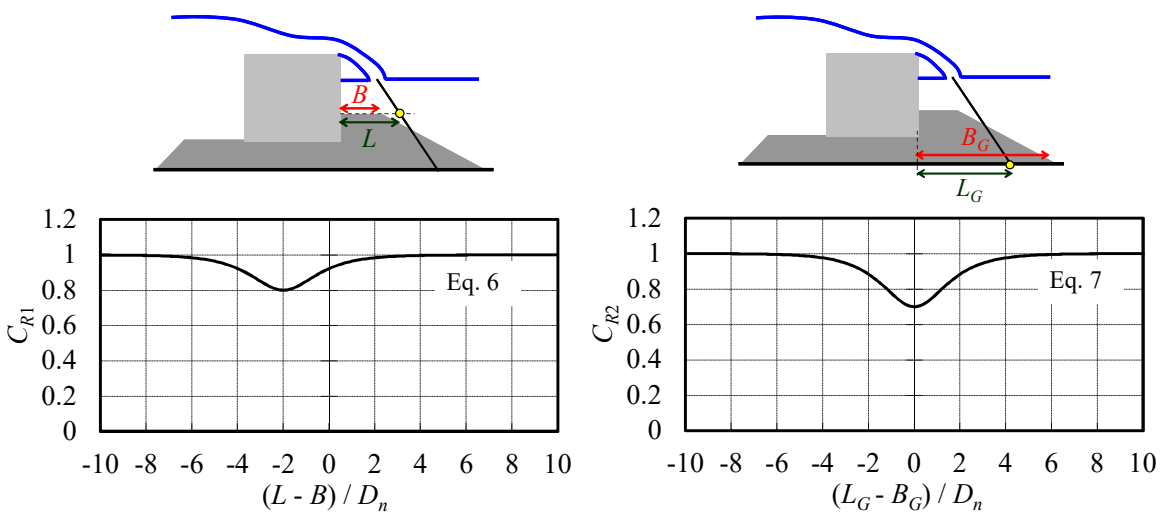

Figure 6. Reduction coefficients of the Isbash number $C_{R 1}$ and $C_{R 2}$, which represent the influence of the impingement position of the water jet.

The second one is to take into account the influence of the thickness of the water jet on the fluid force acting on the armor units. If the thickness of the water jet is sufficiently large relative to the size of the armor units, the fluid force is supposed to be constant irrespective of the thickness of the jet. However, in the case where the thickness of the water jet is small and impinges into only a part of the armor unit, the fluid force is considered to be small even if the flow velocity is the same. In fact, a previous study shows that the stability of the armor units against tsunami overflow is affected by the thickness of the water jet (Mitsui et al. 2016). To take this effect into account, the Isbash number $Y_{0}$ is expressed as a function of the ratio of the thickness of the water jet $b_{1}$ to the nominal diameter of the armor unit $D_{n}$. The Isbash number $Y_{0}$ needs to be determined beforehand by hydraulic model experiments under wide conditions. For example, the experimental results of the Permex and the determined Isbash number are shown in Fig. 7. As can be seen in the figure, the curve of the Isbash number $Y_{0}$ was determined so that it is almost the lower limit of the experimental data at the occurrence of damage.

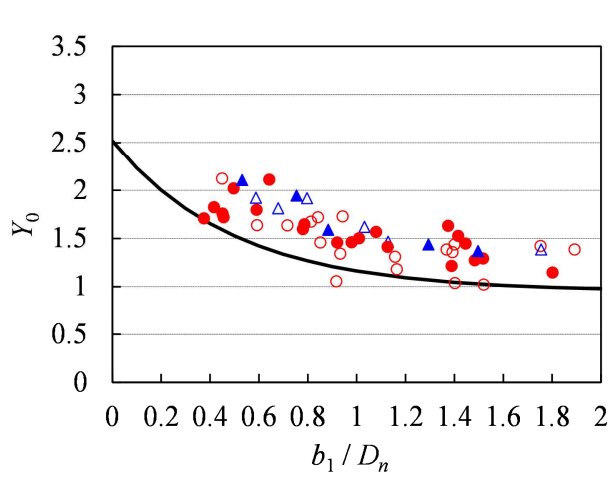

- Breakwater-A, Rectangular caisson

$\triangle$ Breakwater-B, Rectangular caisson

- Breakwater-A, Caisson with parapet

- Breakwater-B, Caisson with parapet

- Y0 curve for Permex 
Figure 7. Experimental results and determined Isbash number $Y_{0}$ of Permex as function of $b_{1} / D_{n}$.

As described above, since the Isbash number $Y$ in the required mass calculation formula is a function of the nominal diameter of the armor unit $D_{n}$, the determination of the required mass is performed in the following procedure. First, assuming the mass of the armor unit, calculate the hydraulic quantities such as the impinging flow velocity $U$ and the thickness of the water jet $b_{1}$. Then obtain the Isbash number $Y$ using Fig. 6 and Fig. 7. Then calculate the required mass $M$ using Eq. 2. It can be judged as stable (or unstable) if the calculated required mass is smaller (or larger) than the assumed mass. If it is judged as unstable, increase the mass of the armor unit and check the stability again.

\section{CALCULATION METHOD FOR TRAJECTORY OF THE OVERFLOW NAPPE, IMPINGING FLOW VELOCITY, AND THICKNESS OF THE WATER JET}

In this section, the calculation method for the trajectory of the overflow nappe, the impinging flow velocity onto the armor units, and the thickness of the water jet, all of which are necessary for calculating the required mass, are shown. First, the water depth $h_{2}$ and flow velocity $u_{2}$ at the rear end of the caisson are obtained from the overflow depth $h_{1}$. Because these values change in a complicated way depending on the shape of the parapet and overflow depth, it is difficult to obtain them by theoretical analysis. Therefore, these values are obtained using calculation diagrams (Mitsui et al. 2017) based on numerical analyses which are pre-conducted in a wide range of conditions. The calculation diagrams are shown in Fig. 8, Fig. 9, and Fig. 10. First, non-dimensional overflow depth and parapet sizes $\left(h_{1} / B_{c}, H_{p} / B_{c}\right.$, and $\left.B_{p} / B_{c}\right)$ are calculated. Then the discharge coefficient $C_{d}$, the ratio of water depth $h_{2} / h_{1}$, and the flow velocity direction $u_{2 z} / u_{2 x}$ at the rear end of the caisson are read from each diagram.
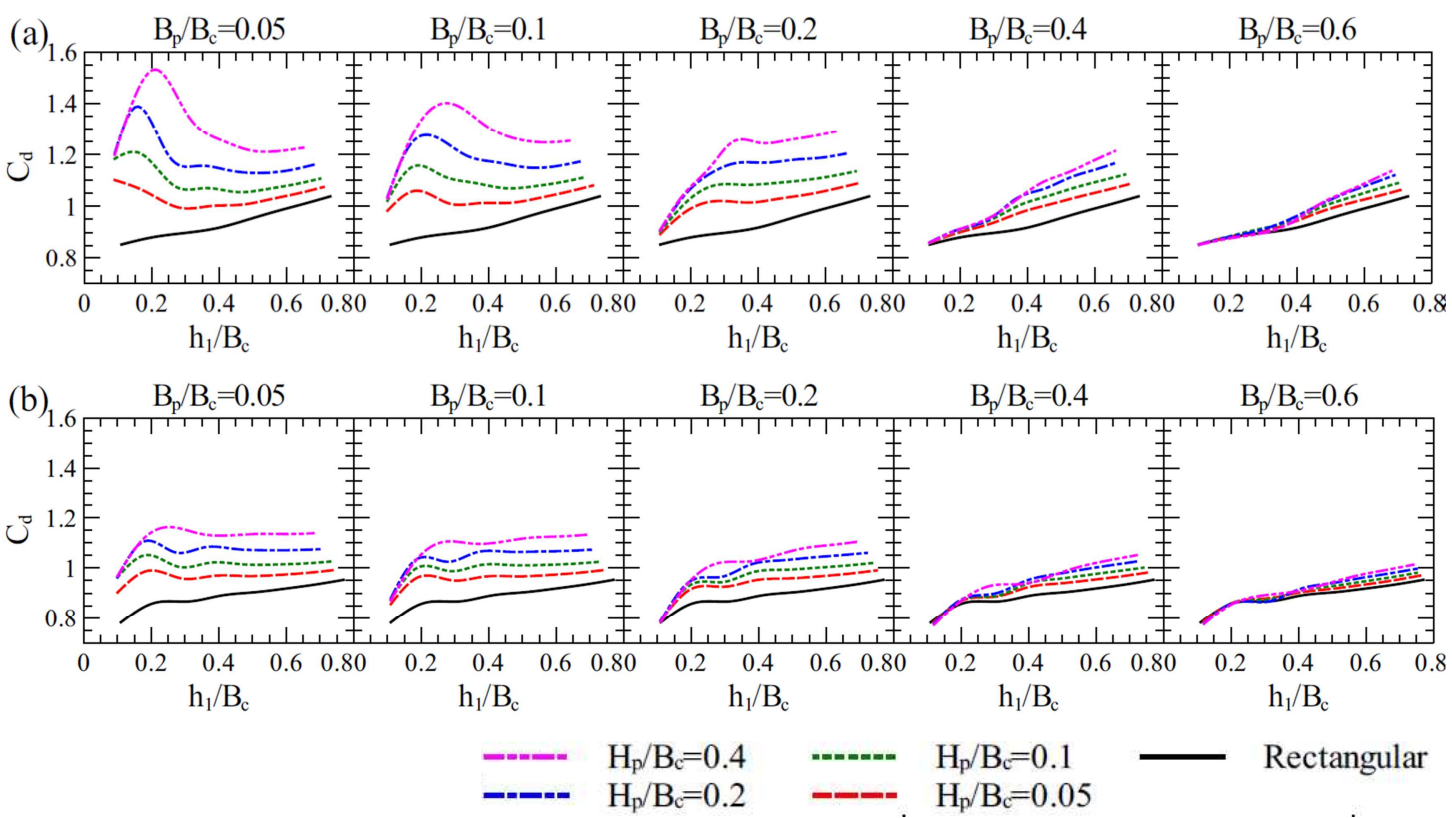

Figure 8. Diagram for discharge coefficient $C_{d^{*}}$ (a): Caisson without wave-dissipating blocks, (b): Caisson covered with wave-dissipating blocks (Mitsui et al. 2017) 

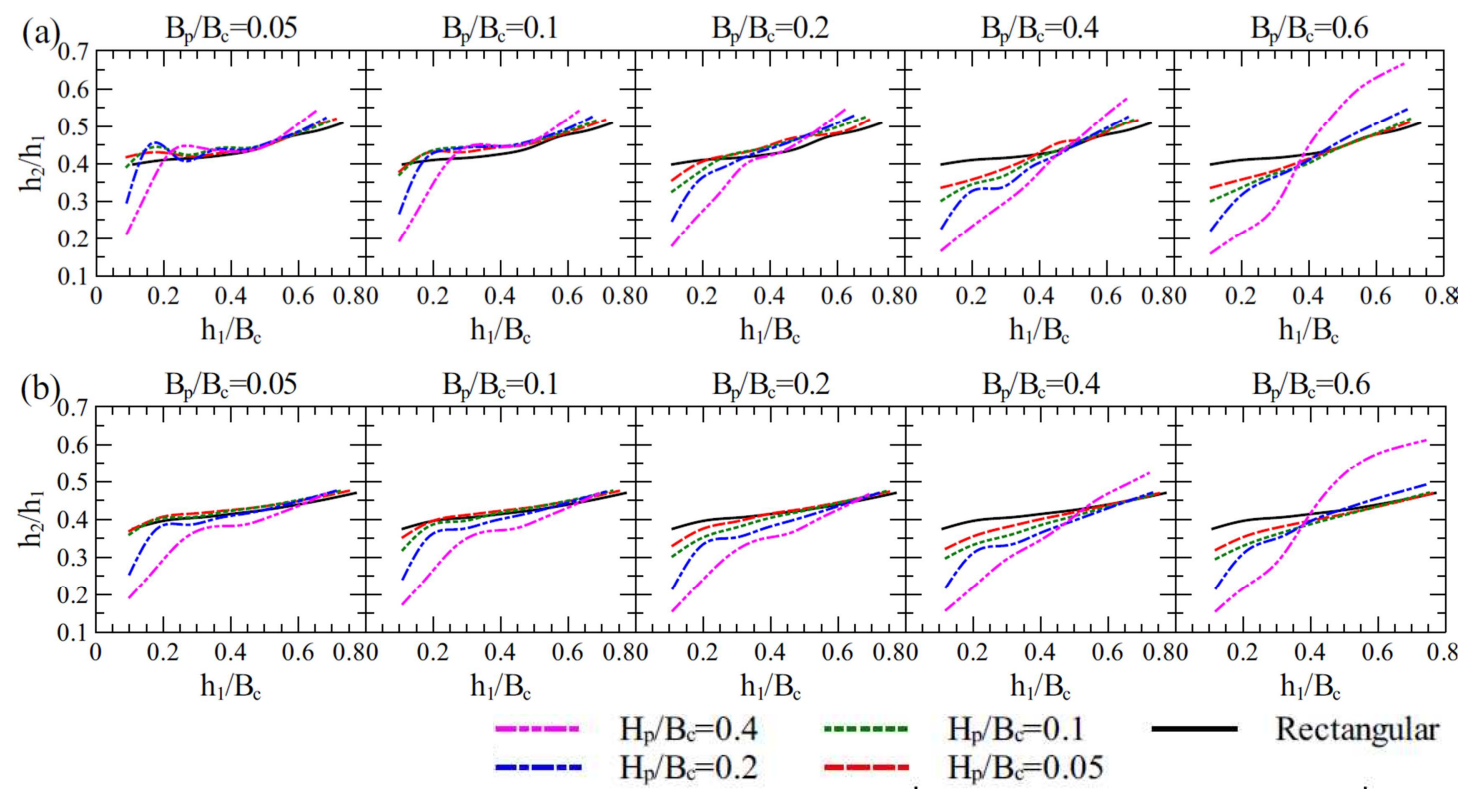

Figure 9. Diagram for $h_{2} / h_{1}$. (a): Caisson without wave-dissipating blocks, (b): Caisson covered with wavedissipating blocks (Mitsui et al. 2017)
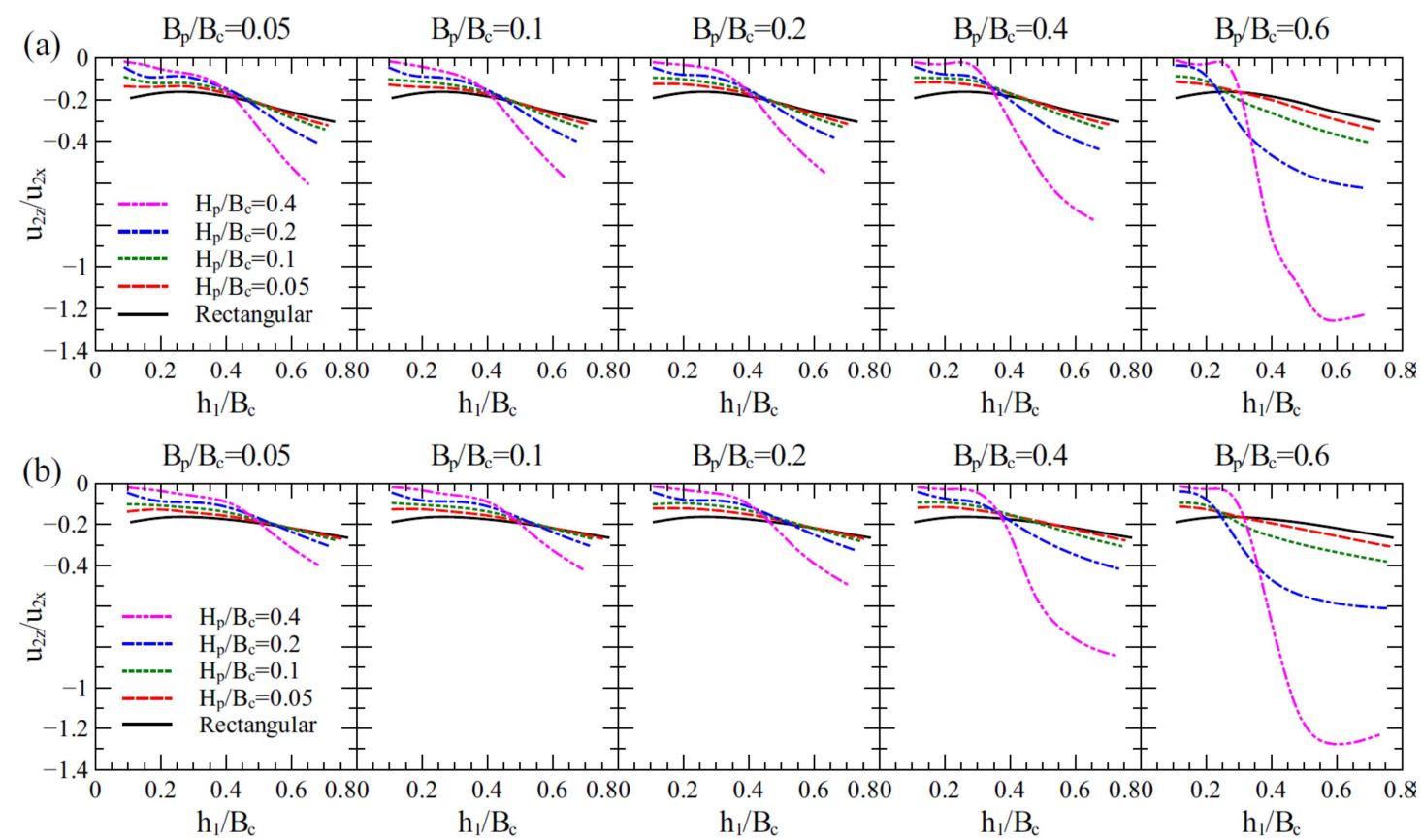

Figure 10. Diagram for $u_{2 z} / u_{2 x}$ (a): Caisson without wave-dissipating blocks, (b): Caisson covered with wavedissipating blocks (Mitsui et al. 2017)

The overflow discharge per unit width $q$ is obtained from the following equation (e.g. Azimi and Rajaratnam 2009):

$$
q=(2 / 3)^{3 / 2} C_{d} \sqrt{g} h^{3 / 2}
$$

The water depth $h_{2}$ at the rear end of the caisson is immediately obtained from $h_{2} / h_{1}$. The flow velocity $u_{2 x}$ and $u_{2 z}$ can be obtained using the $u_{2 z} / u_{2 x}$ read from the diagram and the following equation:

$$
u_{2 x}=q / h_{2}
$$


On the trajectory of the overflow nappe, assuming that the water particles with the above initial velocity at the rear end of the caisson fall freely with a parabolic trajectory, the position of a water particle can be expressed as follows:

$$
x=u_{2 x} t, \quad z=-\frac{1}{2} g t^{2}+u_{2 z} t+d_{1}+\frac{h_{2}}{2}
$$

When the time $t$ is eliminated from Eq. 10, the relation expression of $x$ and $z$, that is, the trajectory of the overflow nappe is obtained as:

$$
z=-\frac{g}{2 u_{2 x}^{2}} x^{2}+\frac{u_{2 z}}{u_{2 x}} x+d_{1}+\frac{h_{2}}{2}
$$

Then the flow velocities $u_{3 x}, u_{3 z}$ and the landing position $x_{3}$ at the water surface inside the harbor $(z=0)$ are obtained as follows:

$$
\begin{gathered}
u_{3 x}=u_{2 x}, \quad u_{3 x}=-\sqrt{u_{2 z}^{2}+2 g\left(d_{1}+h_{2} / 2\right)} \\
x_{3}=u_{2 x} \frac{u_{2 z}+\sqrt{u_{2 z}^{2}+2 g\left(d_{1}+h_{2} / 2\right)}}{g}
\end{gathered}
$$

Further, when the thickness of the water jet at the harbor-side water level is defined as $2 b_{0}$, the $b_{0}$ is calculated as:

$$
b_{0}=\frac{q}{2 \sqrt{u_{3 x}^{2}+u_{3 z}^{2}}}
$$

Assuming that the trajectory of the water jet under the harbor-side water surface is a straight line, the trajectory is expressed by the following equation:

$$
z=\left(x-x_{3}\right) u_{3 z} / u_{3 x}
$$

The impingement position of the water jet at the top of the harbor-side mound $L$, and the impingement position of the water jet at the seabed $L_{G}$ are calculated as follows:

$$
L=\left\{\begin{array}{cc}
x_{3}-d_{2} \frac{u_{3 x}}{u_{3 z}} & : d_{2} \geq 0 \\
u_{2 x} \frac{u_{2 x}+\sqrt{u_{2 z}^{2}+2 g\left(d_{1}+d_{2}+h_{2} / 2\right)}}{g} & : d_{2}<0 \\
L_{G}=x_{3}-h \frac{u_{3 x}}{u_{3 z}} &
\end{array}\right.
$$

Next, the impinging flow velocity onto the armor units $U$ is calculated. First, the coordinates of the impinging position onto the armor units $x_{p}$ and $z_{p}$ are calculated. They can be obtained geometrically from the shape of the mound and the trajectory of the overflow nappe calculated by the above method. For reference, the calculation formula is shown in the appendix. If the water jet passes over the mound and impinges directly onto the seabed, for the sake of convenience, the flow velocity at the impingement position at the seabed is used for the calculation of the required mass. The calculation method for the impinging flow velocity onto the armor units and the thickness of the water jet are shown below. First, a case when the overtopped water jet impinges onto the armor units under the water surface $\left(z_{p}<0\right)$ is assumed. The distance from the landing position of the water jet at the water surface to the impingement position onto the armor units $\bar{x}$ is expressed as follows:

$$
\bar{x}=\sqrt{\left(x_{p}-x_{3}\right)^{2}+z_{p}^{2}}
$$

Regarding the diffusion of the water jet under the water surface, when applying the theory of twodimensional free jet flow (Rajaratnam 1976), the flow velocity under the water surface $U$ can be obtained by the following equation: 


$$
U=\min \left(u_{3}, u_{3} \frac{C_{1}}{\sqrt{\bar{x} / b_{0}}}\right)
$$

where, $C_{1}$ is a constant determined by experiments. In this study, $C_{1}=3.0$ is used considering its suitability to the flow velocity obtained by numerical analysis (Mitsui et al. 2016). Regarding the thickness of the water jet under the water surface, assuming that it expands at 0.1 times the diffusion distance (Rajaratnam 1976), the thickness of the water jet at the impingement position onto the armor units $b_{1}$ is obtained as follows:

$$
b_{1}=b_{0}+0.1 \bar{x}
$$

Next, a case where the crown of the mound is on the water surface and the overtopped water jet impinges onto the armor units above the water surface $\left(z_{p} \geq 0\right)$ is assumed. The diffusion distance under the water surface is:

$$
\bar{x}=0
$$

The impinging flow velocity onto the armor units $U$ and the thickness of the water jet $b_{1}$ are then obtained as follows:

$$
\begin{gathered}
U=\sqrt{u_{2 x}^{2}+u_{2 z}^{2}+2 g\left(d_{1}+h_{2} / 2-z_{p}\right)} \\
b_{1}=q / 2 U
\end{gathered}
$$

\section{VALIDATION OF THE METHOD}

To use this new stability estimation method, it is necessary to determine beforehand the Isbash number $Y_{0}$ for each armor unit by experiments. Fig. 11 shows the curve of $Y_{0}$ as a function of $b_{1} / D_{n}$ for each armor unit. These were determined based on the experimental results including the test cases shown in Table 1.
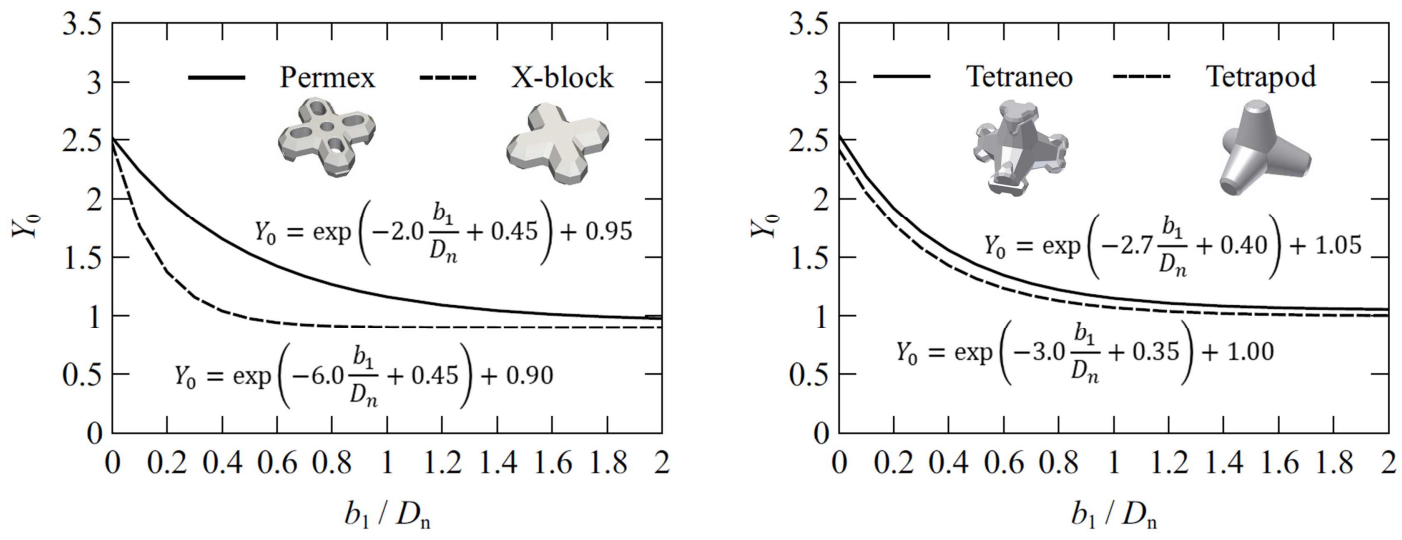

Figure 11. Isbash number $Y_{0}$ for each armor unit as a function of $b_{1} / D_{n}$.

Fig. 12 shows the comparison between overflow depths at the stability limit calculated by this method and the experimental results. It can be seen that they show good agreement regardless of the presence or absence of a parapet. In addition, the calculated results are overall on the safe side, because $Y_{0}$ for each armor unit is determined so as to be approximately the lower limit of experimental data. 


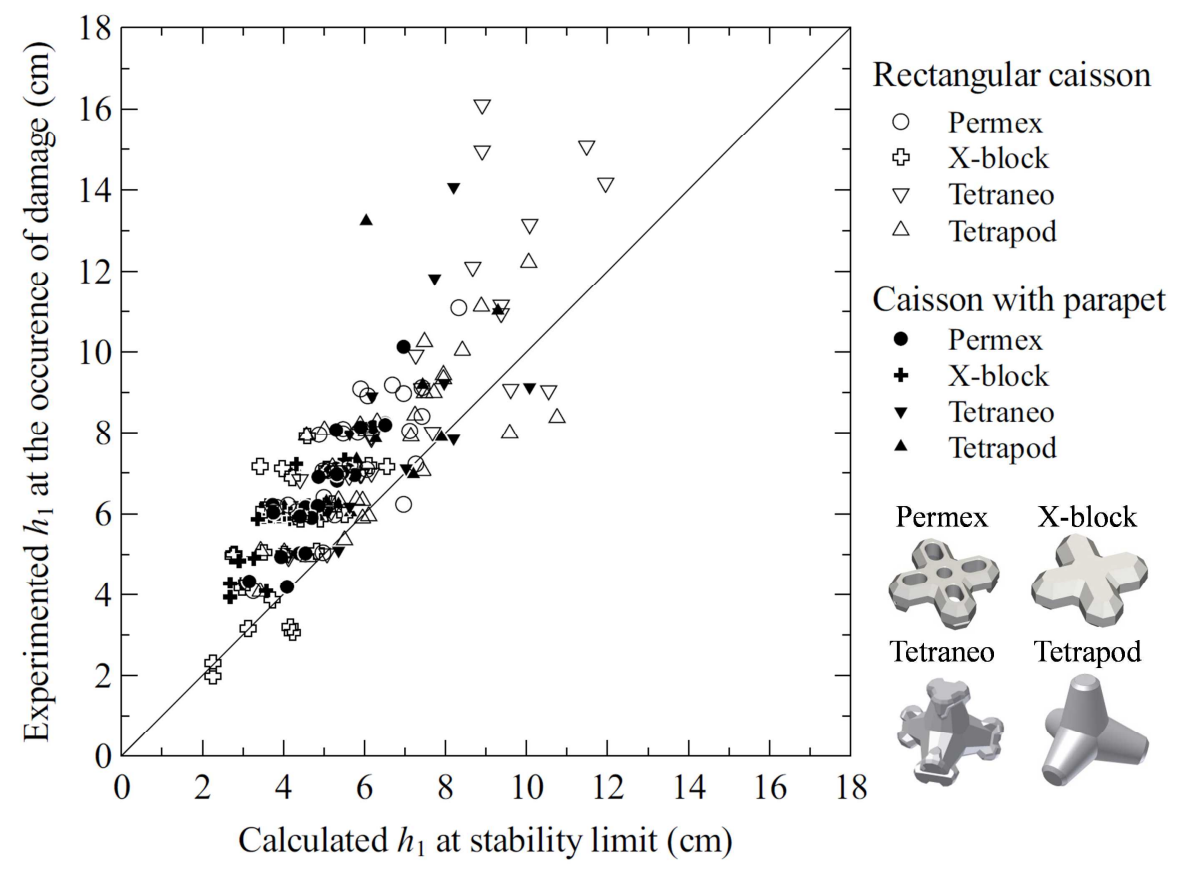

Figure 12. Calculated and experimented overflow depth $h_{1}$ at the stability limit.

The influence of a parapet was investigated using the test case shown in Fig. 4 as an example. Calculation results of the flow velocity at the rear end of the caisson $u_{2}$, the impinging flow velocity onto the armor units $U$, and the thickness of the water jet at the impingement position $b_{1}$ are shown in Fig. 13. The calculated required mass of the Permex in this case is shown in Fig. 14. In the case of the caisson with parapet, since the water above the caisson is accelerated when flowing over the parapet, the flow velocity at the rear end of the caisson $u_{2}$ is larger than that of the rectangular caisson. However, the impinging flow velocity onto the armor units $U$ is larger in the case of the rectangular caisson, which is considered to be mainly due to the small diffusion distance under the water level. On the other hand, the required mass is smaller in the case of the rectangular caisson despite the larger impinging flow velocity $U$. This is thought to be because the thickness of the water jet is relatively small. According to Fig. 14, the overflow depth at the stability limit is calculated as $6.8 \mathrm{~cm}$ for the rectangular caisson and $5.4 \mathrm{~cm}$ for the caisson with parapet. These values are slightly smaller than the experimental results (see Fig. 4), but the tendency with and without parapet are consistent with the experimental results.

Thus, the influence of the parapet on the armor stability is complicated. However, the new stability estimation method can calculate the required mass of the armor units incorporating these effects by considering the physical phenomena such as the impinging flow velocity and the thickness of the water jet.

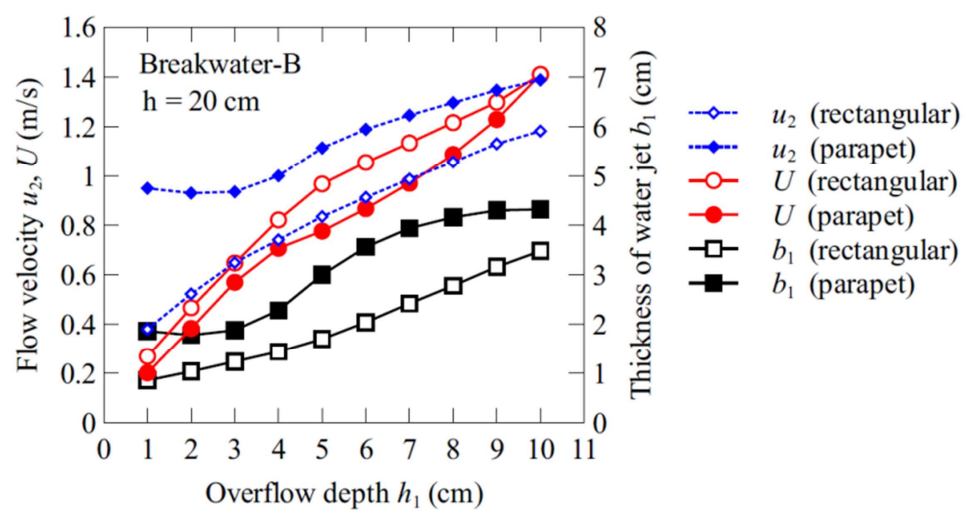


Figure 13. Example of the calculated flow velocity and thickness of the water jet.

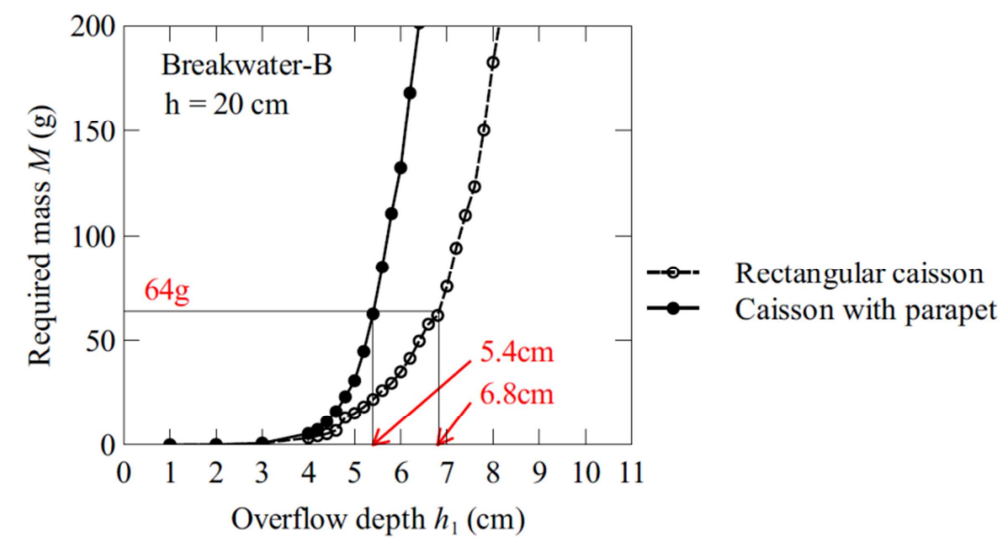

Figure 14. Example of the calculated required mass of Permex.

\section{CONCLUSIONS}

In this study, a new stability estimation method of armor units covering a rubble mound on the rear side of a caisson breakwater against tsunami overflow applicable to caisson with parapet was proposed. The validity of this method was confirmed by experimental results conducted in a wide range of conditions. According to this method, it is possible to directly incorporate the influence of the parapet. Further, it is possible to calculate the required mass of the armor units easily and accurately without requiring numerical analysis.

\section{APPENDIX}

The coordinates of the impinging position onto the armor units $x_{p}$ and $z_{p}$ can be calculated as follows:

(1) if $d_{2} \geq 0$ :

(1.1) if $L \leq B$ :

$$
x_{p}=L, \quad z_{p}=-d_{2}
$$

(1.2) if $L>B$ :

(1.2.1) if $L_{G} \leq B_{G}$ :

$$
x_{p}=\frac{\frac{u_{3 z}}{u_{3 x}} x_{3}+\frac{B}{\cot \alpha}-d_{2}}{\frac{u_{3 z}}{u_{3 x}}+\frac{1}{\cot \alpha}}, \quad z_{p}=\left(x_{p}-x_{3}\right) \frac{u_{3 z}}{u_{3 x}}
$$

(1.2.2) if $L_{G}>B_{G}$ :

$$
x_{p}=L_{G}, \quad z_{p}=-h
$$

(2) if $d_{2}<0$ :

(2.1) if $L \leq B$ :

$$
x_{p}=L, \quad z_{p}=-d_{2}
$$

(2.2) if $L>B$ :

(2.2.1) if $x_{3} \leq B-d_{2} \cot \alpha$ :

$$
x_{p}=\frac{-b+\sqrt{b^{2}-4 a c}}{2 a}, \quad z_{p}=-\frac{x_{p}-B}{\cot \alpha}-d_{2}
$$

where, 


$$
\begin{aligned}
& a=\frac{g}{2 u_{2 x}^{2}}, \quad b=-\frac{u_{2 x}}{u_{2 z}}-\frac{1}{\cot \alpha}, \quad c=-d_{1}-\frac{h_{2}}{2}+\frac{B}{\cot \alpha}-d_{2} \\
& \text { (2.2.2) if } x_{3}>B-d_{2} \cot \alpha \text { : } \\
& \text { (2.2.2.1) if } L_{G} \leq B_{G} \text { : } \\
& x_{p}=\frac{\frac{u_{3 z}}{u_{3 x}} x_{3}+\frac{B}{\cot \alpha}-d_{2}}{\frac{u_{3 z}}{u_{3 x}}+\frac{1}{\cot \alpha}}, \quad z_{p}=\left(x_{p}-x_{3}\right) \frac{u_{3 z}}{u_{3 x}} \\
& \text { (2.2.2.2) if } L_{G}>B_{G} \text { : } \\
& x_{p}=L, \quad z_{p}=-d_{2}
\end{aligned}
$$

\section{REFERENCES}

Arikawa, T., K. Okada, and K. Shimosako. 2014. Stability of armour blocks on the widening works behind breakwater under tsunami overflow, Journal of JSCE, Ser. B2 (Coastal Engineering), Volume 70, Issue 2, I_941-I_945 (in Japanese).

Azimi, A.H., and N. Rajaratnam. 2009. Discharge characteristics of weirs of finite crest length, Journal of Hydraulic Engineering, Volume 135, Issue 12, 1081-1085.

Coastal Engineering Research Center. 1977. Shore Protection Manual, U.S. Army Corps of Engineers, U.S. Government Printing Office, Vol. II, 7_213-7_216.

Hamaguchi, M., S. Kubota, A. Matsumoto, M. Hanzawa, M. Yamamoto, H. Moritaka, and K. Shimosako. 2007. Hydraulic stability of new flat type armor block with very large openings for use in composite breakwater rubble mound protection, Proceedings of $5^{\text {th }}$ Coastal Structures International Conference, CSt07, Venice, Italy, 116-127.

Higashiyama, K., I. Hasegawa, and S. Inagaki. 2013. Study of harbor side mound scoring by tsunami overflow, Journal of JSCE, Ser. B3 (Ocean Engineering), Volume 69, Issue 2, I_377-I_382 (in Japanese).

Isbash, S.V. 1932. Construction of Dams by Dumping Stones into Flowing Water, Sci. Res. Inst. Hydrotech. Leningrad, Translated by A. Dovjikov, U.S. Army Corps of Engineers, 1935.

Matsuda, S., W. Nishigori, A. Matsumoto, M. Saito, M. Matsuoka, and M. Hanzawa. 2003. New stability formula for rubble mound armor units of composite breakwaters, Proceedings of Coastal Structures 2003, Portland, Oregon, United States, 330-342.

Matsumoto, A., M. Hanzawa, N. Hirose, S. Kubota, S. Noboru, and J. Mitsui. 2016. Recent development of new concrete blocks in Japan, Proceedings of the Vietnam-Japan Workshop on Estuaries, Coast, and Rivers 2016, Ho Chi Minh City, Vietnam, 48-59.

Mitsui, J., A. Matsumoto, M. Hanzawa, and K. Nadaoka. 2014. Stability of armor units covering rubble mound of composite breakwaters against a steady overflow of tsunami, Proceedings of $34^{\text {th }}$ International Conference on Coastal Engineering, Seoul, Korea, structures.34.

Mitsui, J., A. Matsumoto, and M. Hanzawa. 2016. Derivation process of the Isbash formula and its applicability to tsunami overtopping caisson breakwaters, Proceedings of the $6^{\text {th }}$ International Conference on the Application of Physical Modelling in Coastal and Port Engineering and Science (Coastlab16), Ottawa, Canada.

Mitsui, J., S. Kubota, A. Matsumoto, and M. Hanzawa. 2017. Numerical analysis on hydraulic characteristics of tsunami overtopping caisson breakwaters, Proceedings of Coasts, Marine Structures and Breakwaters 2017, 1121-1130.

Rajaratnam, N. 1976. Turbulent Jets, Elsevier Scientific Pub. Co., Amsterdam, 304p.

Satoh M., H. Yoneyama, I. Hasegawa, and S. Inagaki. 2012. Scouring of harbor side mound by tsunami and countermeasure for common breakwater, Journal of JSCE, Ser. B3 (Ocean Engineering), Volume 69, Issue 2, I_252-I_257 (in Japanese). 